\title{
7
}

\section{Musical agency and collaboration in the digital age}

\section{Tom Roberts and Joel Krueger}

\section{Introduction}

In 2019, the musician Holly Herndon released her third full-length album, Proto. In addition to input from two other human artists, the album had a fourth collaborator: an artificial neural network named Spawn. The software had been trained over several years to generate and manipulate the cavernous choral soundscapes that brought Proto widespread critical acclaim. Spawn's role in each stage of the music-making process was neither completely predictable nor completely under Herndon's control; her vocal contribution its tone, pitch, rhythm and dynamics - was often novel, original and surprising. ${ }^{1}$ Herndon describes Spawn as 'a performer ... an ensemble member. So I would say that I collaborated with a human and an inhuman ensemble' (Funai 2019).

Here, we consider how seriously we ought to take assertions like this one. Can we really conceive of AI systems as legitimate collaborators in the skilled project of making art? Do they have the kinds of creative agency, autonomy and expressive power that characterize membership of an artistic ensemble? ${ }^{2}$ 
In the next section, we rehearse some reasons why there has been a reluctance to give affirmative answers to these questions why, that is, computational systems have been taken to have an impoverished status, lacking capacities essential to true artistic agency (see Boden 2007). Following this, we explore the view that even when attributions of creativity and autonomy to artificial systems are not literally true, they can instead be fictionally true. Those who work alongside generative systems like Spawn and those who enjoy the musical fruits of such collaboration are participants in an elaborate game of make-believe, wherein the non-human contributor is imaginatively conceived as being a real improviser, a real singer, a real musician. Taking this line allows us to give credence to testimony like Herndon's, and to better understand the production and appreciation of music that has a partially nonhuman origin.

\section{Musical agency}

Why might Spawn be regarded as deficient, relative to the skills and capacities of more traditional makers of music? Here, we sketch three related characteristics that lie at the heart of musical agency in familiar contexts: embodiment, emotional expression and autonomy. Human agents typically exemplify these dimensions in the course of making music, to a greater or lesser degree, but it is hard to see how they might be manifested by a robot, an algorithm or a neural net.

Firstly, the performance of traditional acoustic music is an embodied, energetic and visceral affair. Instruments are blown, struck, plucked, strummed and twanged with a rhythm and vitality that reflects physical engagement with the music. The musician and her instrument are in motion together; motion shaped by grip, posture, muscle and breath. When an ensemble of musicians plays in unison, moreover, their bodies attune to one another in the service of a collective aesthetic aim (Clayton et al. 2020). And of course the body itself may be an instrument - the voice, the stamping of the feet, the clapping of the hands.

Secondly, music can be a vehicle for emotional expression: a powerful tool for articulating the affective states of a listener, 
composer or performer. Facility with a musical instrument can expand and enhance an agent's expressive repertoire, giving her a new language with which to convey her feelings. Pitch, loudness, rhythm and timbre can enrich the musician's emotional vocabulary. And music's affective content is carried to the ear of the listener, too, who may in turn be moved, saddened, uplifted or called to action.

Thirdly, music typically arises from acts of creative autonomy, governed by the artist's choices and intentions. Although not every note or phrase is the product of conscious deliberation, the artist controls the overall process of conception, composition and performance and bears responsibility for the music's final form. ${ }^{3}$ Various layers of intentional input are possible: a composer may devise and transcribe the melody, for example, and arrange parts for the orchestra to follow. An individual player can choose the tempo and dynamics of a piece, and when to diverge from or embellish a score. Sometimes these choices are made collectively, in advance or on the fly, in discussion or rehearsal.

Our claim is not that every musical performer, nor every member of an ensemble, must always exhibit each of these three features to a high degree. Sometimes, after all, a musician may simply follow a score and submit her own agency to that of the conductor or band leader; and sometimes a performance may be a tightly controlled technical feat, with little room for emotional colour.

What we do suggest is that embodiment, expressivity and autonomy are characteristic aspects both of how we conceive of musical agency and of how we experience musical performance in a range of ordinary cases. We hear music, that is, as the product of an act of singing or playing, shaped by the artist's intentional agency and delivered through embodied, expressive behaviour. This agential character, moreover, shows up in our appraisal of a work or performance as an achievement (Huddleston 2012; Roberts 2018). For instance, a technical achievement of dexterity, breath control or coordination, or as the virtuous product of originality, honesty or insight. Music is not only an unfolding pattern of sound, it is the result of effort, intention and expertise; and it is conceived of, perceived and evaluated in these terms by the audience.

In sum, musical agency has several facets that come in degree: it involves a package of features that implicate intention, expression and cognition, where these features are most typically borne by embodied human subjects. 
What do these remarks tell us about Spawn and her kin? They may encourage a pessimistic position regarding the creative and expressive powers of artificial systems. A neural network housed in a box is not alive, inhabits no organic body, lacks projects and concerns, feels no emotions and has no evaluative capacities. It cannot tap its fingers; sway to a beat; or feed on the energy of its bandmates. While it has generative capabilities, it cannot select or refine its own outputs on the basis of their aesthetic interest, ${ }^{4}$ let alone commit to artistic projects that have wider cultural or political resonance. In the absence of conscious inner states, it is unable to express a concernful perspective - to communicate feelings of loss, say, or to voice its joyful triumph. In accepting this pessimism, one might concede that talk of AI artistry, collaboration, expression and creativity is simply false and misleading, and to reserve these terms for full human agents. Yet this concession appears to be at odds with what we hear from artists like Holly Herndon, who seem willing to attribute a degree of artistry, agency and autonomy to their artificial collaborators.

\section{Fictional agency, fictional artistry}

We propose that an alternative, fictionalist approach can illuminate the artistic and appreciative practises that grow up around AIdriven music. The fictionalist view enables us to say that it can be advantageous for an artist or listener to engage in the fictional pretence that there is AI musical agency - ranging from performance and interpretation to full creative composition - even if we accept that this is not literally true.

In the philosophy of mind, fictionalism is the view that even when we attribute inner mental states to other humans, we are engaging in a complex act of pretence. We don't sincerely judge that there are internal beliefs and desires, for example, but it is extremely productive, for the purposes of explanation and prediction, to treat one another as though we have them. The imaginative game of make-believe in which we collectively participate is a false but highly useful tool for navigating the interpersonal world. Fictional make-believe is a more involved mental process than the 'detached imagining' we perform when, for example, we conceive an abstract 
philosophical thought experiment. Make-believe has deeper ties to behaviour: we interact physically with the material 'props' of the fictional setup (Walton 1990) and these interactions in turn generate new imaginings, governed by the rules of the game we are playing (Toon 2016).

While we have no wish to defend fictionalism's systematic antirealism here, ${ }^{5}$ we will argue that there is value in applying it to the particular domain of artificial systems, including those that appear to be operating creatively. The claim is that even if, strictly speaking, artificial musical collaborators lack an autonomous, expressive point of view, it can be fruitful for an artist to participate in the fiction that they do exhibit this richer agential status.

Notice, as a preliminary, how natural it is to describe in fictionalist terms our anthropomorphization of entities such as robots and videogame characters. When we are presented with an on-screen humanoid or a mechanical creature whose behaviour appears goaldirected, intelligent or otherwise non-random, we are strongly inclined to react to them as though they were a psychological agent. We imaginatively entertain that the cute robot dog is a friendly pet who wants to play; and that the zombies in the videogame have a murderous intent and a thirst for revenge. If pushed, we would surely deny that ascriptions like these are literally true; but it is nonetheless part of the fun that - for a while at least - we act as though they are.

Within a fiction, we might consider even a rather rudimentary artificial system to have a quite sophisticated mental life - short and long-term plans, memories, preferences, moods and so forth. ${ }^{6}$ And our own psychological and behavioural reactions are shaped by the role we adopt in the fiction, too - in our displays of sympathy, attachment or solidarity towards the robot pet we have been raising, for example, or the fear and hostility we feel towards the antagonists in the videogame. Entering into the make-believe with enthusiasm and goodwill, we suggest, is often the best way to make the most of the interactive opportunities afforded by novel technologies. Treating a virtual or artificial entity as if it had folk-psychological states makes it possible to form certain new relationships with that entity - to consider it a friend or foe, for instance - and allows us to predict, explain and interpret the entity's behaviour without attending to its underlying physical or computational basis, ${ }^{7}$ in real time, much like we do when we interact with human agents. 


\section{The phenomenology of fictional agency}

Using Herndon as a case study, we now consider some ways of conceiving how we might collaborate with AI systems. ${ }^{8}$ Fictionalism can help to make sense of some illuminating tensions in how Herndon seems to experience and describe her collaboration with Spawn. It can also help to better understand why Spawn - and AI systems more generally - offers collaborative relationships that are richer, and potentially more artistically productive, than those afforded by other non-human resources sometimes brought into the music-making process.

\section{Performative and compositional collaboration}

It is not uncommon to speak of non-human resources as involved in the creative music-making process (de Mori 2017). Indigenous peoples may describe songs as originating from guardian or ancestral spirits; Western composers such as Brahms portray themselves as a conduit for music that flows directly from God; musicians like Brian Eno use card-based methods ('Oblique Strategies') to prompt creative thinking; while Pauline Oliveros's 'Deep Listening Band' performed in subterranean vaults that shaped their music's reverberating character.

In these cases, non-human resources are said to play an important role in animating the creative process. But it is unlikely that the resources would be described using the agential vocabulary of thinking, feeling or intending. ${ }^{9}$ However, collaborations with artificial systems like Spawn appear to more readily invite folk psychological attributions. One reason for this is that they furnish practical, experiential and temporal (both synchronic and diachronic) forms of collaboration that are richer and more complex than those offered by other non-human resources forms of collaboration, that is, that feel closer to engaging with a human agent than does 'collaborating' with, say, a deck of cards. Whereas the latter may provide a useful stimulus - a cryptic remark on an Oblique Strategies card may prompt an insight that helps to overcome a creative impasse - their causal input remains limited, and their interactive possibilities static. In contrast, AI systems like Spawn offer deeper forms of engagement closer to 
the collaborative dynamics that unfold between human agents. Not only are they structurally more complex - in being iterative, reciprocal and temporally extended - they can appear to bear the hallmarks of agency and mindedness, seeming to have a musical voice of their own.

Herndon and human colleagues first train Spawn by creating data sets made up of Herndon's own voice and those of an ensemble. They then feed sonic building blocks (vocals, percussive elements, etc.) into Spawn, who draws on these data to sing over these building blocks - often in unpredictable and surprising ways. Herndon then splices this Spawn-produced output into tracks (sometimes recording more vocals in response), or feeds her manipulations back into Spawn in order to generate further outputs.

Despite the important role Spawn plays in the creative process, Herndon is clear that she is not sentient: 'I don't see Spawn as a human baby. I see Spawn as an artificial intelligence baby .... It's something that can surprise and can have the feeling of creativity and ingenuity, but there's no consciousness yet' (Friedlander 2019).

Words like these suggest that our fictionalist characterization is a complicated matter. What, then, is the value in applying fictionalism to creative- and artistic-looking procedures like music-making? One significant value is phenomenological. Fictionalism can illuminate the felt character of the sorts of collaborative experiences artists like Herndon describe, including what may initially appear to be some puzzling features of her descriptions of these experiences. For, despite her protests to the contrary, some things Herndon says suggest that she does, in fact, adopt an anthropomorphic fictionalist stance towards Spawn when collaborating with her. This is why their collaborations work as effectively as they do.

Recall first that Herndon is comfortable speaking about her partnership with Spawn as a genuine collaboration. She says:

I consider Spawn as a performer, as an ensemble member ... I certainly consider those collaborations. When you write a score, then somebody reads it, human or inhuman, there's an interpretation happening there. Things always come out slightly different than when you imagined it. That's how I've used Spawn as a performer. It's collaborative in that sense.

(Funai 2019) 
Here, Herndon characterizes her collaborative relationship with Spawn in terms of interpretation and performance. Spawn performs her take on the music that Herndon creates. Herndon affirms this characterization elsewhere, saying that 'we see Spawn as an ensemble member, rather than a composer. Even if she's improvising, as performers do, she's not writing the piece. I want to write the music!' (Hawthorne 2019).

Herndon is clear that although she herself is the composer responsible for the choices and intentions behind the music, ${ }^{10}$ Spawn may be said to interpret the piece by manipulating some of its elements - the way a musician may manipulate, say, the tempo or dynamics of a score when performing live in response to the audience or their own aesthetic impulses. Talk of 'reading' and 'interpreting' the score, we suggest, may already be non-literal terms like these suggest a cognitive sophistication that we might be unwilling to attribute to Spawn. If so, the fictionalist view permits us to say that Herndon is not mistaken or speaking falsely when she uses such language; instead, it is a make-believe that Spawn is an ensemble member.

Sometimes, moreover, Herndon also seems comfortable describing her collaboration with Spawn not just in terms of performance but also of composition. In other words, Spawn's role is felt to be more than just an expressive vehicle articulating Herndon's pre-formed vision; rather, she (Spawn) contributes something more substantial, much closer to creative agency. Herndon acknowledges that in the case of Spawn, the boundary between performance and composition can blur:

There's often this extreme hierarchy between composer and performer ... I'm not saying this is non-hierarchical - my name's on it, I'm choosing which performances land on the record - but ideas aren't generated in a vacuum. The idea of one person being the entirety of something is just really limited.

(Hawthorne 2019)

What Herndon seems to suggest here is that the creative agency driving the music-making process is not limited to one causal origin. It is instead a collective enterprise, something distributed across multiple agents - one of whom happens to be non-human.

Similarly, Herndon tells us elsewhere: 
There is some improvisation that happens when Spawn interprets something that I write. It's not a binary between composing and performing. There is an entire gray area of interpretation and the improvisation. However, I prefer to stay on the end of maintaining the composition ... I like to maintain that autonomy and that agency of being able to grow and change my aesthetic and change my form ....

(Funai 2019)

This quote captures the tension in how Herndon seems to experientially relate to Spawn. On one hand, Herndon is keen to maintain a grip on creative agency and authorship, conceiving of Spawn's role in terms of (mere) performance. However, on the other hand, she also seems to concede that Spawn generates goods that are somehow essential for driving the creative process: resources that contribute to her own growth as an artist.

This idea of modulating her 'aesthetic and form' in order to animate the creative process is found in yet another description: 'I'm singing through a system I've made [i.e. Spawn]. I can morph between human and animal and digital. I can sing through plants' (Hawthorne 2019). ${ }^{11}$ The 'morphing' Herndon describes is, as we'll see below, a modulation of agency - a transformation, guided and scaffolded by Spawn's ongoing input, that helps her get into the creative space needed to compose her distinctive music.

How, then, should we understand this tension in Herndon's reports? Is her collaborative relationship with Spawn primarily performative, compositional or somehow both? Here, fictionalism gains further traction. We propose - as the best interpretation of available evidence on Herndon's attitudes and practice - that when making music, Herndon adopts a fictionalist stance towards Spawn. Although she clearly knows that Spawn is not a conscious subject, she nevertheless treats Spawn as if she has a mental life - as if she is a kind of agent with aesthetic beliefs, desires, intentions, etc. - in order to temporarily become part of a larger structure of collaborative agency. ${ }^{12}$ By adopting a fictionalist stance, Herndon allows Spawn to take over aspects of performance and composition to contribute novel (and often unexpected) goods that open up previously unseen creative pathways. Incorporating Spawn into the creative process in this way allows Herndon to experiment with temporary agencies ('I can morph between human and animal 
and digital'); this experimentation is a central part of the musicmaking process. We now consider the phenomenology of this experimentation in more detail.

\section{Experimenting with (fictional) agencies in music}

Note first that using music to experiment with our agency is not something confined to music-making with artificial systems. We regularly do something like this when listening to music, too. There is a sense in which we enter into music (Krueger 2009). We experientially inhabit it and let it take over and govern different aspects of our agency. Briefly considering how so will shed light on our experimentation with fictional agencies when collaborating musically with artificial systems.

There is a tight link between the form of our musical engagements and the way we experience and manipulate different aspects of our agency within these engagements (Krueger 2014). For example, several scholars defend the idea that musical experience can involve the presence of an imagined 'other' (Levinson 2006), a 'persona' (Cochrane 2010) or 'virtual agent' (Leman 2007) with whom we identify when immersing ourselves in a musical work.

Music is also a powerful resource for the construction of the self and social relationships. As DeNora (1999) puts it, music is a 'technology of the self' - a resource or 'material that actors use to elaborate, to fill out and fill in, to themselves and to others, modes of aesthetic agency and, with it, subjective stances and identities' (p. 54). Varieties of musical practices central to everyday life are, in this way, tied to the construction, experience and manipulation of our agency.

For our purposes, the key point is this: music furnishes resources that allow us to experiment, in various ways and at multiple timescales, with forms of agency - including, in the context of AI-driven music-making, fictional agencies. When composing, we suggest that Herndon treats Spawn as if she has a mental life (beliefs, desires, intentions, creative impulses, etc.), in order to bring her more deeply into the creative process, to feel like Spawn is more deeply involved - and in so doing, generate new interpretive and compositional possibilities. However, this fictionalist stance also 
shapes Herndon's self-experience. By allowing herself to become drawn up into this larger collaborative structure - by offloading part of the creative process onto Spawn - Herndon can, in turn, experiment with her own agency. She can 'morph between human and animal and digital' and 'sing through plants' as she temporarily inhabits new creative spaces opened up by this organic-digital collaboration.

To develop this idea further, we can use Nguyen's (2019) work on games and agency. Nguyen argues that a similar process unfolds when we play games, especially computer games offering visually immersive worlds and rich story- and character-driven narratives. For Nguyen, games specify modes of agency for players to adopt: their rules, practices, goals and supporting abilities 'shape the agential skeleton which the player will inhabit during the game' $(2019,423)$. For example, undertaking projects, tasks or quests alone or with others; developing a character's skills, abilities or motivations; interacting with non-player characters to advance the storyline, etc., allows players to take on alternative agencies in a controlled and limited way. Players fictionally become things they're not and do things they can't normally do because the game space furnishes resources supporting this sort of agential transformation. They can engage in these transformative practices, Nguyen argues further, because human agency is not fixed. It turns out to be 'modular and moderately fluid. We have the capacity to set up temporary agencies, layered within our larger agency, and submerge ourselves within them' $(2019,426)$.

There are, of course, structural and phenomenological differences between playing games and making music with AI. One difference concerns the respective aims of these activities. When playing games, a central part of the enjoyment experience is the experience of striving. Game designers not only create the world in which individuals will act but also structure their practical agency their abilities, goals and values $(2019,438)$. Enjoyment of games is tied to a balanced striving experience: too much freedom and the game will become tedious; too little and it is frustrating. We take on temporary agencies for the sake of the intrinsic value of the experience of struggling within the gameworld; we enjoy the strenuousness of the play, the tension, uncertainty and (assuming we achieve our goal) release of finally realizing the fruits of our striving. 
In the case of collaborating musically with artificial systems, it's unclear that striving plays the same role. Spawn is set up to contribute novel and unpredictable responses, and to challenge her human collaborators, by forcing them to respond to her outputs in unanticipated ways. This tension and uncertainty fuels the creative energy driving the music-making process. It may be thought of as a kind of striving - in much the way that improvising with a new musical partner (or partners) involves a kind of striving as individuals work to get into a groove with one another by learning to adapt and respond to each others' idiosyncratic styles. However, it's unlikely that Herndon et al. are interested in the intrinsic value of this striving itself. Rather, the striving is a means towards some further end namely, to make music. In this context, the striving experience has an instrumental value that distinguishes it from playing games.

\section{Conclusion}

Fictionalism helps to illuminate why Herndon is motivated to adopt a make-believe stance towards Spawn. By treating Spawn as if she is an agent with (some degree of) creative autonomy, as if her input is to be taken as seriously as that of a human collaborator, Herndon generates the aesthetic tension, the striving, needed to drive the music-making process. Crucially, this striving has a rich diachronic and reciprocal character that distinguishes it from the stimulus-response structure that characterizes other non-human contributions to music, such as Eno's Oblique Strategies cards or Oliveros's underground caverns. Spawn provides ongoing (and often unpredictable) resources that give Herndon a felt sense that Spawn is a participatory member of the creative process, generating ideas and aesthetic energy that drives the process along. Part of this feeling also seems to arise from the interactive possibilities Spawn affords. Herndon can play with and manipulate Spawn's output - riff on it - and potentially feed her riffing back into Spawn in order to generate further output. This interactive and iterative dynamic helps understand why Herndon may be inclined to adopt a fictionalist stance towards Spawn, despite her firm insistence that Spawn is not sentient.

Fictionalism can also help illuminate another dimension of the collaborative process. By adopting a fictionalist stance, Herndon 
is also able to temporarily inhabit agential structures - Nguyen's 'agential skeleton' - that enable her to experiment with and explore structures of her own agency. By singing through the technological resources Spawn provides, she can generate and inhabit richly textured soundworlds that would otherwise be unachievable. She can experiment with different modes of creative agency and gain insight into her own creative process as she responds to what Spawn feeds back to her.

For Herndon, then, this complicated collaborative relationship with Spawn, and the forms of agential experimentation it affords, is not something that alienates her from her humanity. Rather, it affirms it. She tells us that 'technology should allow us to be more human together rather than alienating us further. So many of the products and so many of the habits that we have with our technology pushed us towards alienation. But really, it could free us up to be more human and more emotional together by taking some of the work, essentially' (Funai 2019). In this context, fictionalism is one source of such freedom. ${ }^{13}$

\section{Notes}

1 Herndon and her team use female pronouns for Spawn.

2 While our interest in these questions is philosophical, it is not difficult to see that they may have legal or economic implications - can an AI claim intellectual property rights?

3 This is true even with techniques of composition that introduce elements of randomness or chance, such as Iannis Xenakis's stochastic or aleatoric music, or the generative music created by electronic musicians like Autechre, Keith Fullerton Whitman and Emily A. Sprague.

4 For discussion of the selection phase of creativity, see e.g. Boden and Edmonds (2009), Wheeler (2018).

5 One of us has argued against a core assumption motivating fictionalist approaches to other minds: that folk psychological pretence is necessary because we have no way of directly accessing others' mental states (e.g. Krueger 2012, 2018). We also note that, as a philosophical hypothesis about our attributions of mental states, fictionalism is constrained by and consistent with scientific evidence of the kinds mentioned in the text. Debates about the basis of such attributions arise, like many in the philosophy of mind, because the evidence from psychology and neuroscience does not fully settle the issue. 
6 There is some evidence that we are more inclined to attribute cognitive than emotional states to AI (e.g. Bakpayev et al. 2020).

7 That is, by adopting the intentional rather than the physical stance (Dennett 1987).

8 Herndon is not the only electronic musician who collaborates with an artificial system. We choose to address her work here due to the wideranging and nuanced descriptions she has given of her collaborative creative process. We acknowledge the limitations of relying on the testimony of a single artist, offered in a non-academic context, and in future work we hope to engage with further musicians and performers.

9 The case of God, or guardian or ancestral spirits, is more complicated since individuals are inclined to speak of these entities in folk psychological terms. Since our focus is on material artefacts and technologies of music-making, we do not consider these cases further.

10 Moreover, we might interpret her insistence that 'I want to write the music!' as implying that to attribute creative authorship to Spawn would somehow be inauthentic (Boden 2007).

11 By 'singing through plants', Herndon means that Spawn allows her to experientially inhabit and manipulate field recordings in real time, using her voice.

12 Something like this is what Herndon seems to have had in mind when, during a recent online video discussion along with her collaborator, Mat Dryhurst, she described this experience as 'getting lost in the romance' of making music with Spawn. Holly Herndon and Mat Dryhurst in conversation. Everywhere it is Machines series, School of Performing \& Digital Arts, Royal Holloway, University of London, 1 April 2021.

13 Many people provided helpful feedback on previous drafts of this chapter. We are particularly grateful to Lucy Osler, Giovanna Colombetti, Adrian Currie, Juan Diego Bogotá, John Sutton, Kath Bicknell, Emily Cross, Kohinoor Darda, Michael Wheeler, Ian Maxwell and participants in the 'Collaborative Embodied Performance Work-in-Progress’ workshops and University of Exeter 'Culture and Cognition' reading group.

\section{References}

Bakpayev, M., T. H. Baek, P. Van Esch and S. Yoon (2020), 'Programmatic Creative: AI Can Think but It Cannot Feel', Australasian Marketing Journal (AMJ), April. https://doi.org/10.1016/j.ausmj.2020.04.002.

Boden, M. A. (2007), 'Authenticity and Computer Art', Digital Creativity $18(1): 3-10$. 
Boden, M. A. and E. A. Edmonds (2009), 'What Is Generative Art?' Digital Creativity 20 (1-2): 21-46.

Clayton, M., K. Jakubowski, T. Eerola, P. E. Keller, A. Camurri, G. Volpe and P. Alborno (2020), 'Interpersonal Entrainment in Music Performance', Music Perception 38 (2): 136-94.

Cochrane, T. (2010), 'Using the Persona to Express Complex Emotions in Music', Music Analysis 29 (1-3): 264-75.

De Mori, B. B. (2017), 'Music and Non-Human Agency', In Ethnomusicology: A Contemporary Reader, Volume II, ed. Jennifer C. Post, 181-94. London: Routledge.

Dennett. (1987), The Intentional Stance. Cambridge, MA: MIT Press.

DeNora, T. (1999), 'Music as a Technology of the Self', Poetics 27 (1): 31-56.

Friedlander, E. (2019), 'How Holly Herndon and Her AI Baby Spawned a New Kind of Folk Music', Fader, 21 May. Available online: https:// www.thefader.com/2019/05/21/holly-herndon-proto-ai-spawn-interview.

Funai, M. (2019), 'Holly Herndon on Merging the Worlds of Music and AI', Dropbox Blog, October 10. Available online: https://blog. dropbox.com/topics/our-community/holly-herndon-interview (accessed 21 June 2021).

Hawthorne, K. (2019), 'Holly Herndon: The Musician Who Birthed an AI Baby', The Guardian, 2 May. Available at: https://www.theguardian. com/music/2019/may/02/holly-herndon-on-her-musical-baby-spawn-iwanted-to-find-a-new-sound (accessed 21 June 2021).

Huddleston, A. (2012), 'In Defense of Artistic Value', The Philosophical Quarterly 62 (249): 705-14.

Krueger, J. (2009), 'Enacting Musical Experience', Journal of Consciousness Studies 16 (2-3): 98-123.

Krueger, J. (2012), 'Seeing Mind in Action', Phenomenology and the Cognitive Sciences 11 (2): 149-73.

Krueger, J. (2014), 'Affordances and the Musically Extended Mind', Frontiers in Psychology 4: 1003.

Krueger, J. (2018), 'Direct Social Perception', In Albert Newen, Leon de Bruin and Shaun Gallagher (eds), Oxford Handbook of 4E Cognition, Oxford: Oxford University Press.

Leman, M. (2007), Embodied Music Cognition and Mediation Technology. Cambridge, MA: MIT Press.

Levinson, J. (2006), Contemplating Music. Oxford: Oxford University Press.

Nguyen, C. T. (2019), 'Games and the Art of Agency', The Philosophical Review 128 (4): 423-62.

Roberts, T. (2018), 'Aesthetic Virtues: Traits and Faculties', Philosophical Studies 175 (2): 429-47. 
Toon, A. (2016), 'Fictionalism and the Folk', The Monist 99 (3): 280-95. Walton, K. L. (1990). Mimesis as Make-Believe: On the Foundations of the Representational Arts. Cambridge, MA: Harvard University Press. Wheeler, M. (2018), 'Talking about More than Heads: The Embodied, Embedded and Extended Creative Mind', In B. Gaut and M. Kieran (eds), Creativity and Philosophy, 230-50. New York: Routledge. 